\title{
Students' Decision-Making About Postgraduate Education at G University in China: The Main Factors and the Role of Family and of Teachers
}

\author{
Dan Liu ${ }^{1}$ W. John Morgan ${ }^{2,3,4}$
}

Published online: 15 December 2015

(c) The Author(s) 2015. This article is published with open access at Springerlink.com

\begin{abstract}
The paper draws on findings from a case study which explored factors influencing students' decisionmaking of postgraduate (PG) education at G University in China. Both questionnaires and follow-up interviews were used for data collection. This paper reports the main reasons for students' choices of subject and institution for PG education, and the influences of families and teachers, and of guanxi in their decision-making. The findings show that both families and teachers play important roles in shaping students' decision-making about PG education. It provides insights into students' decision-making about higher education embedded in the Chinese culture of Confucianism.
\end{abstract}

Keywords Family habitus - Teacher habitus .

Students' decision-making · Postgraduate education

\section{Introduction}

Over the past 20 years, the number of higher educational institutions (HEIs) in China has doubled from 1045 in 1995 to 2491 in 2013 (NBSC 2014). Correspondingly, the

Dan Liu

ttxd112@nottingham.ac.uk; liudansure@gmail.com

W. John Morgan

MorganJ74@cardiff.ac.uk; John.Morgan@nottingham.ac.uk

1 School of Education, University of Nottingham, Nottingham, UK

2 UNESCO Chair of Political Economy and Education, University of Nottingham, Nottingham, UK

3 China Policy Institute, University of Nottingham, Nottingham, UK

4 School of Social Sciences, Cardiff University, Cardiff, UK undergraduate enrolment in regular HEIs rose from over 2.9 million in 1995 to 24.6 million in 2013 (NBSC 2014). The rapid expansion of the enrolment of undergraduates has also stimulated students' enthusiasm for postgraduate (PG) studies. The number of enrolled students for master degrees increased over tenfold from 145,443 in 1995 to 1,793,953 in 2013 (NBSC 2014).

To meet the fast growing demands for HE in China, students have increasingly been required to pay a greater share of the cost of their education (Wu and Zheng 2008). The average tuition fee in regular HEIs for each undergraduate rose from 500 Yuan $^{1}$ in 1995 to 5000 in 2000, which was equivalent to the average annual urban income and twofold of the annual rural income ( $\mathrm{Wu}$ and $\mathrm{Zheng}$ 2008). It is worth noting that the actual costs were much higher than the above official figure and might have increased in the subsequent years (Wu and Zheng 2008). It is estimated that the tuition fees contributed to around $34 \%$ of the income of all the HEIs in recent years (Altbach and $\mathrm{Yu}$ 2012). This means that HEIs in China also face the necessity to position themselves in the increasingly competitive market to ensure enough funding for their services and activities. In order to optimize their services, they need to understand how students make choices about where and what to study.

From the autumn of 2014, the PG higher education in China has undergone a fundamental change as it began to practice the fee-charging policy for its students. It is for the first time that the PG education had been funded, via a system of student grants and loans, instead of wholly by the state. It marks the end of the state-funded public funding system of PG education with its implications for social justice in access and opportunity in higher

\footnotetext{
${ }^{1}$ Yuan, Chinese monetary unit, 1 pound equals 9.2 Yuan at present.
} 
education (Wu and Morgan 2015). Under the new policy, it is regulated that the tuition fees for master's degrees and doctorates in academic disciplines are capped at 8000 and 10,000 Yuan, respectively (Anonymous 2013). The new system makes the PG education more expensive and there has been speculation that the applicant numbers might fall in the subsequent years. Thus, it is useful to investigate the possible factors influencing students' decision-making about PG education in the changing circumstances.

Explorative in essence, the paper investigates the main factors influencing Chinese students in choosing their subject and institution for PG education together with the roles of family and teacher habitus, and guanxi in this process.

\section{Literature Review}

\section{Student Choice of Higher Education}

Explanations for factors influencing students' choice of domestic higher education can be mainly divided into frameworks that emphasize economic, rational choices and those emphasizing social (or socio-cultural) reproduction (Smyth and Banks 2012). From a rational choice perspective, students are seen as rational consumers who make decisions based on the principle of utility maximizing. However, this approach has received many critics and the central argument here is that whether the students' choices of higher education are only made on the basis of the rational calculation of costs and benefits (Obermeit 2012; Fredman 2015). The social reproduction approach, in contrast, focuses on different economic, cultural and social capital possessed by different social classes that influence students' dispositions to learning and further to their educational choices (Bourdieu 1977). Both theoretical approaches, however, have devoted little attention to the impact of institution (Smyth and Banks 2012). Although Bourdieu's theory of 'habitus' has been extended to 'institutional habitus', little is known about the way in which institutional habitus plays out at the school level (Smyth and Banks 2012).

In addition, Bourdieu argues that habitus only operates in relation to a social field, consisting of 'a set of objective, historical relations between positions anchored in certain forms of power (or capital)' (see Hoskins 2013, p. 62). The same habitus can produce very different 'practices' in different 'fields' because of such interconnected nature of habitus to the field (Jenkins 2002; Reay 2004). Given that Chinese students' choices of domestic PG education are shaped by their own cultural and social context, a social field which is different from that of the Western contexts, exploring Chinese students' choices of domestic PG education, has become a necessity. There are a growing number of research studies on Chinese students' decision-making about higher education in recent years (Liu 2010; Lee and Morrish 2012; Liu et al. 2013; Fang and Wang 2014). ${ }^{2}$ However, the majority were about Chinese students' choice of higher education for overseas studies. Research studies specifying Chinese students' decision-making about domestic higher education are quite limited, with the exceptions being Lai et al. (2014) and To et al. (2014). These studies, however, were conducted mainly at the undergraduate level and outside mainland China, and thus could not reveal the views and attitudes of students there towards undertaking PG education. This paper attempts to bridge this gap by reporting findings from a case study at G University in the southern part of China, focusing on main factors influencing students in making choices about subject and institution for PG study, together with the influences of family, teachers and guanxi.

\section{The Theoretical Framework}

This paper uses the theoretical framework of 'habitus' developed by Bourdieu (1986) and the its extended versions of 'family habitus' and 'institutional habitus' developed by Reay (1998). Given the contextualized nature of this study, the concept of guanxi, a Chinese variant concept of social capital, another key concept of Bourdieu, is also used in the framework.

The concept of 'habitus' was first conceptualized by Bourdieu in his theory of 'cultural capital'. Cultural capital refers to the cultural advantage an individual enjoys and which is acquired through education, family and other sources that confer social power and status (Bourdieu 1986). Habitus is defined as 'a habitual or typical condition, state or appearance, particularly of the body' (quoted in Jenkins 2002, p. 74). They are durable and transposable dispositions acquired in one's early life, which are embodied through an individual's manner, styles and language (Oliver and Kettley 2010; Jenkins 2002).

Reay (1998, p. 527) extended the habitus to familial/family habitus as the 'deeply ingrained system of perspectives, experiences and predispositions family members share'. Some studies have focused on the role of cultural and familial habitus in student choice of higher education (Shaw 2012; Gao 2011). McDonough (1997) then puts forward the concept of 'organizational habitus', which was

\footnotetext{
${ }^{2}$ All the resources concerning Chinese student decision-making are in English on the grounds that a thorough literature research indicated that no Chinese language sources exist.
} 
later renamed 'institutional habitus' by Reay (1998), to differentiate the impact of individual schools on both pupils' and parents' habitus, practices and choices (see Atkinson 2011). Institutional habitus could be understood as the impact of a social group or class on individuals' behaviour which is mediated through an organization (Reay et al. 2001; Smyth and Banks 2012). Some researchers have applied this empirically (Reay et al. 2001; Oliver and Kettley 2010). Recently, there has been a trend to bring both family and institutional habitus together to account for student choice about higher education (Smyth and Banks 2012); however, related empirical research is still limited, especially in the context of China.

A further issue relates to the role of guanxi (a Chinese variant of social capital) in Chinese students' educational choices. This is crucial in understanding Chinese behaviour in social, political and organizational contexts (Huang 2003). Bourdieu (1986, p. 249) defined social capital as the 'aggregate of the actual or potential resources which are linked to possession of a durable network'. Although guanxi does have its own cultural connotations which will be discussed later, it is similar to social capital. It refers to 'a dyadic, particular and sentimental tie that has the potential of facilitating favour exchanges between the parties connected by the tie' (Bian 2006, p. 312). Guanxi in this sense is seen as networks and social resources, through which one could attain benefits and favours (Bian 1997). This echoes the concept of social capital, which also considers the social ties and networks possessed by individuals and which can be used to gain favours and benefits.

Although the role of family and institutional habitus as well as guanxi has been explored separately to explain student choice of higher education, few studies have combined them to examine students' decision-making about higher education, and still fewer focus on PG education. This paper adopts the combined framework of both the family habitus and the institutional habitus together with guanxi to better understand how students' decisionmaking about PG education is made. It highlights the role of family habitus and teacher habitus as well as guanxi in shaping students' decision about undertaking PG education, especially in shaping students' choices of subject and institution for PG study.

\section{Methodology}

\section{Research Questions}

Our research questions were:

(1) What were the main factors influencing student choice of programme and institution for PG study?
(2) How and to what extent did the family background and teachers influence such choices?

A mixed-method approach was adopted. The first question was addressed through an exploratory questionnaire to explore students' main reasons for making choices about programme and institution for PG study. The second question was addressed using a semi-structured interview, which considered the influences of family background and teachers on student decision-making.

\section{Participants}

616 Questionnaires were distributed to the whole PG students across the 15 faculties and schools of G University. In total, 381 questionnaires were returned with a return rate of around $60 \%$. The G University in Guangdong (GD) Province was chosen as the research cite for the following reasons. First, GD Province is one of the most economically prosperous regions in mainland China. The population of GD is socio-economically diverse. Second, the G University is a key provincial university in GD Province, where school choice and competition are actively taking place. Third, as a key provincial university, the $G$ University attracts a large number of students with diversified background across other provinces in mainland China. Lastly, the researcher's previous studying experience as a PG at this university would make the case accessible.

The demography of the 381 students varied in terms of gender, age, ethnicity, undergraduate university, hometown, parents' education, work experience and ways of entrance. Table 1 (see "Appendix 1" section) provides the general demographic information of the participants for the survey.

\section{Data Collection}

The field research was conducted in two phases which involved an initial survey and a follow-up semi-structured interview. To answer the first research question, a questionnaire was developed based on extensive literature review and the Chinese context. The main factors influencing students' choices of subject for PG study and institution should include the following: personal interest; entry requirements and school admission rate; employment prospects of the subject; cost of package; the academic reputation of this subject and institution; quality of faculty; quality of resources and amenities; convenient location of the institution; the advice from others, such as parents, teachers and friends; and 'other' which students could specify (Obermeit 2012; Liu et al. 2014). Based on that, a questionnaire was designed with two main parts. The first 
part was used to obtain general background information about the students, such as their age, gender, field of study, hometown, parents' educational degree and parents' occupations. The second part consisted of two main questions asking students to choose the most three important reasons both for choosing their programme and institution for $\mathrm{PG}$ education and then rank them according to their importance separately.

To answer the second research question, semi-structured interviews with thirty students, who had indicated their willingness to participate at the end of the questionnaires, were conducted. Based on the class classification criterion suggested by Sheng (2015), the participants for the interview were classified into working-class and middle-class based on their parents' educational backgrounds and occupations. From each faculty or school, there were two students interviewed. During the interview, the students were asked not only to elaborate on their main reasons for their specific choices of programme and institution, but also to comment on the influences of the significant others in their decisionmaking process. Each interview lasted between 45 and $60 \mathrm{~min}$. All the interviews were audio-recorded with the participants' consent and were later transcribed by the authors. Table 2 (see "Appendix 2" section) provides the general demographic information about the participants in the interview.

The research aim and questions were submitted to an ethical approvals committee, and full consent was granted by the host university. The participants in this study were voluntary, and were well informed about the research.

\section{Data Analysis}

The survey data were analysed with descriptive analysis of the SPSS. Firstly, the answers of the 381 participants were put into the SPSS. The respondents' answers were then coded as 1, 2, 3 or 0 . For example, if student A's answers were $\mathrm{A}, \mathrm{B}$ and $\mathrm{D}$ according to their ranking, then numbers 1, 2 and 3 were assigned to options A, B and D, respectively. The remaining options not chosen by student A were coded as 0 . Secondly, options A, B and D were then recoded with a new value according to their importance. For example, the options A, B and D were recoded with values of 10, 7 and 5, respectively. Next, the importance of each option was calculated from the sum of the weight value, for example, the sum of the weight value of the option A was 2695 (see Fig. 1). Thus, the three most important reasons for students to pursue PG education could be obtained according to the sum of the weight value of each option. Finally, a graph was produced based on the sum of the weight values under each option, which was shown in the section of the findings.
For the qualitative data, they were coded and analysed with thematic analysis. Firstly, all the interview transcripts were thoroughly read and subsequently coded. Based on that, a list of the core themes and subthemes was produced. These themes are later categorized according to the research questions and those suitable ones for this study were selected for presentation. To ensure the validity, the coding process was re-checked by one of the author's colleagues. At the same time, the author kept referring back to the earlier codes to ensure that the codes were applied consistently.

\section{Findings}

\section{Students' Main Reasons for Choosing Subject and Institution for PG Study}

As shown in Fig. 2, according to the ranking of the importance of each option, students choose their subject of study mainly out of personal interest. Easier to find a job through studying this subject was ranked second and good income prospects ranked third. In addition, entry requirements and the reputation of the subject were also important concerns in choosing their specific field of study.

In terms of the main reasons for choosing $G$ University, as shown in Fig. 3, according to the ranks allocated to the importance of each option, the three most important reasons were the academic reputation of the institution, location of this university and education quality of the faculty. Excellent resources and amenities of the university as well as entry requirements were also important reasons why students chose G University as the place to study.

\section{The Influence of Family Background and Teachers}

\section{Family Influence}

Parents played an important role in shaping some students' motivation for undertaking PG education.

My father went to university and was a high school teacher; he thought the higher education degree, the better. I thought it might have a connection with his age- when you entered university then, you were in a safe box. You would be arranged a job and live a better life than those who did not go to university. Naturally, I took his advice and made up my mind to continue for PG studies. (Qiao, a middle-class female student)

Seven participants, whose parents received higher education, mentioned the positive influence of family habitus and the stimulating family learning environment on their choice of subject for PG studies. They picked up good reading and 


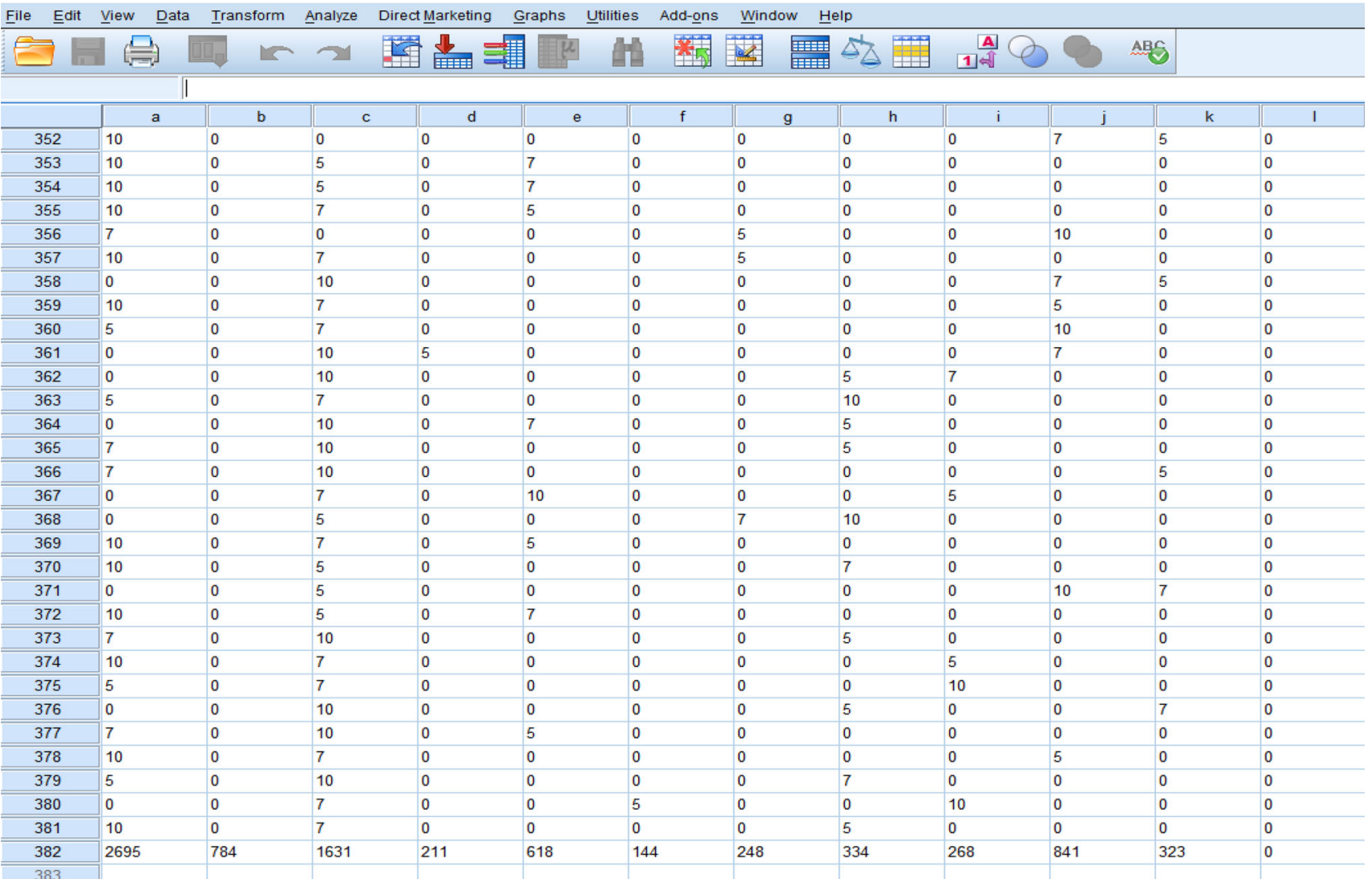

Fig. 1 An example of the analyzing procedure of the quantitative data

Fig. 2 Students' main reasons for choosing their subject of study

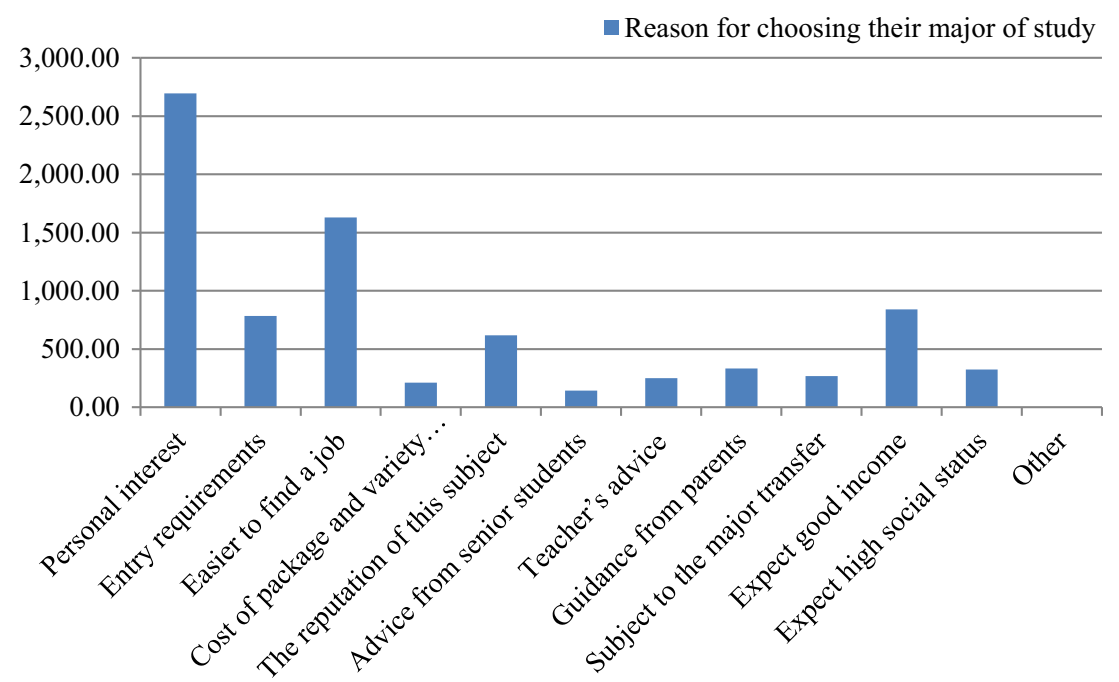

learning habits from their parents who regularly read books at home.

I developed a reading habit at an early age. It was because of the influence of my family environment. Whenever my parents came back home from work, they would read books ...Immersed in this environment, I developed the habit of reading and kept it till now...I was especially interested in English and naturally I chose English Interpretation both for undergraduate and postgraduate studies... (Yang, a middle-class female student) 


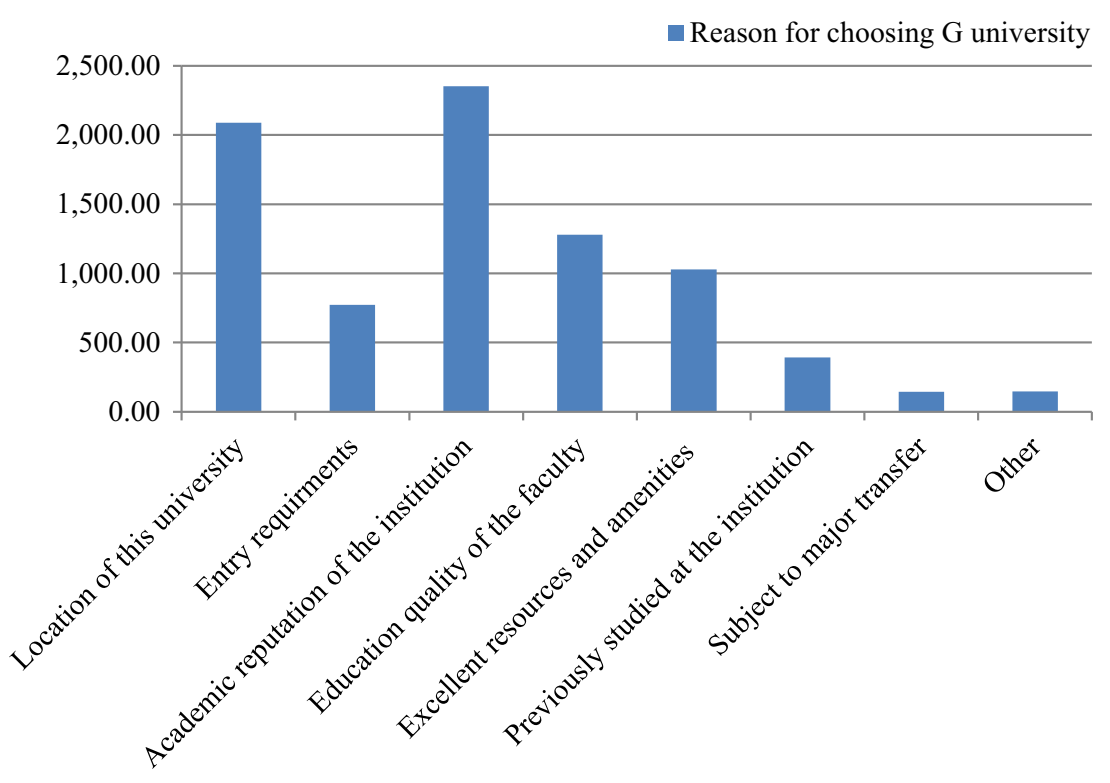

Fig. 3 Students' main reasons for choosing G University

Participation in cultural activities, aided by objectified cultural capital at home, could acquaint children with cultural cues, and lead to the further development of related knowledge and skills. Thus, the knowledge increment and confidence accumulated from family learning directed students' development of specific interest in certain aspects, which further influenced their choices of subject for undergraduate and PG studies.

I was interested in English and I thought this had a connection with my family. My father was a teacher. He attached importance to my learning. He bought me a lot of tapes, English reading materials, and the recorder for me when I was in primary school [Students began to receive English classes at middle school]. Naturally, I became quite interested in it. Thus, I laid a solid foundation for English before middle school. Maybe because of this, I knew more than other students in English, and I kept learning it all the way through. (Fei, a middle-class female student)

In addition, parents with higher educational degrees would be more conscious and attentive to cultivate academic skills in their children at an early age.

When I was young, I received a love letter from a boy in my class. Most of the children would hide it from their parents as parents would not allow their children to fall in love at an early age. I let my parents know and to my surprise, they read the letter carefully and used it for teaching me to learn Chinese characters. You know, they picked out the wrong characters and told me how to correct it ... (Wang, a middle-class female student)

In contrast, for those parents who did not go to university and thus had no real understanding of the choice process, they could not provide any specific suggestions for their children's choice of PG education.

My parents did not give any suggestion on my choice of postgraduate education as they had no knowledge about that. (Fang, a working-class female)

Some families used guanxi to gain access to PG studies. Three of the interviewees mentioned they got inside information or the 'key points' when preparing for the PG entrance examinations as they have family guanxi.

I chose the subject at $\mathrm{G}$ University because my uncle on my mother's side was at this university. He was a professor at the Centre for European Studies. My uncle then introduced some of his students to me and asked me to consult them about what and how I should prepare for the examinations. (Fangzi, a middle-class female)

\section{Teachers' Influence}

The findings revealed that teachers' beliefs and dispositions were influential in shaping some students' motivation for undertaking PG education.

I attended a training class for Business English at X University [a national elite university]. Once I had some questions written on my notebook for my 
teacher's information, the cover of which was written 'Y University' [a non-elite university] where I studied for my undergraduate education. When he saw this, he pointed the words on my cover and told me that I should not be self-content with a university degree from the Y University. His words inspired me to go to an elite university for postgraduate studies. (Jie, a working-class female)

In addition, the teachers' personal beliefs and encouragement were found to be important in developing some students' interest in certain subject, which further influenced their choice of subject for higher education.

Several of my middle and high school teachers were very kind to me and helped me a lot in study... One of my head teachers who taught me English gave me a lot of learning chances. For example, she recommended me to the training class which was exclusive for top students, although I was not up to that rank. As a result, I developed an interest in English and continued it both for undergraduate and postgraduate studies. (Song, a working-class male)

More importantly, the teaching method and style were found to be influential in shaping some students' interest towards certain areas.

We had a Linguistic class in the third year of my undergraduate studies. I liked it very much. The teacher's class was very attracting as what she taught was very easy to understand and interesting. Her class made me want to explore Linguistics in great depth. As a result, I decided to pursue postgraduate studies in that area. (Jiang, a working-class female)

For some students, the interest developed through their teacher at secondary school studies would often lead to success in certain subjects for their later studies, which further directed their choice of subject for PG studies.

I was very good at English during high school because our high school English teacher's class was quite fascinating. Apart from teaching us the knowledge about text books, she taught us lots of extracurricular knowledge. My English was not good during middle school; however, after having her classes, I made prominent progress...Thus, I chose English all the way through postgraduate studies. (Lan, a working-class female)

Several other students mentioned that guanxi established with their undergraduate supervisor during their UG studies contributed to their success in the PG entrance examinations.

I thought $\mathrm{G}$ University would be much easier for me as I had all the resources here, the most important of which was my supervisor. As long as I could pass the preliminary exam I wouldn't have any problem in the second round of examinations. He told me who was responsible for setting up the topics for the preliminary exam. Then I found that person and he told me the important topics for review (I can't specify any more). In the end, I got 140 marks out 150 and ranked second in the preliminary exam. (Wei, a workingclass male)

\section{Conclusions and Discussion}

This paper has explored the main factors influencing student choice of subject and institution for PG education, together with the influences of family and teacher habitus, as well as guanxi on such choices. The quantitative data revealed the main reasons for students' choices of subject and institution for PG study. The qualitative data illustrated how such perceptions and choices of PG education were shaped by their family and institutional habitus as well as guanxi.

The quantitative data showed that apart from 'personal interest', potentially good employment prospects signalled by 'easier to find a job', 'expect good income', 'academic reputation of the institution' and 'education quality of the faculty' constituted one of the main reasons for students' choices of subject and destination for PG study. Although the results are similar to others in the Western society (see Hemsley-Brown and Oplatka 2015), as having been shown in the literature review, empirical research on Chinese students' choices of domestic higher education was quite limited. This research bridges the research gap by revealing how students' such choices were shaped by the Chinese social and cultural context as discussed in what follows.

The qualitative data showed the impact of family habitus on students' decision-making about higher education in China. It is consistent with the findings of literature in the Western context which argues that family lifestyles and cultural consumption patterns have important impacts on children's cultural formation, motivation to learn and even on their choices of higher education (Dimaggio 1982; Shaw 2012). However, relatively few empirical studies unpacked how this is played out at Chinese students' choices of higher education. This article found that those families with more cultural capital and educational resources benefited their children in the formation of good learning habit and knowledge increment, and even shaped their children's intention for university at an early age. In contrast, those parents with limited cultural capital were unable to provide any guidance to their children's route to learning, less alone to their PG educational choices. This may not be surprising as cultural capital is considered to be 
unequally embedded in different social hierarchies and associated social positions.

In addition, the qualitative data revealed how guanxi, both family guanxi and guanxi established in the school context, facilitated student's access to PG studies. Although the impact of guanxi has been examined in the educational context (Tsang 2013; Wu 2013), related research study revealing its impact on Chinese students' access to PG education has not been seen. It found that students from middle-class backgrounds generally cited the facilitating role of family guanxi in their choices of PG education, while students from the working-class backgrounds, usually exempt from such family guanxi, more frequently cited the influence of guanxi established with their teachers in such choices. This should be understood in terms of the cultural connotations of guanxi, which implies the exchange of favour (renqing) and the obligatory reciprocity (huibao) (Qi 2013). Family guanxi are usually strong and close as they are driven by affective motives involving more frequent renqing exchange, whereas non-family guanxi are weak and distant as they are driven by instrumental motives involving less frequent renqing exchange (Chen et al. 2013). Students tend to choose the strong and close network where they feel more comfortable than the weak and distant one, unless when there is no such choice available, in which circumstance, the latter would be used.

The family is the main place where the habitus is produced and mediated through socialization into norms and values (Bourdieu 1977). However, Ball (2003) pointed out that habitus is 'durable but not eternal', which suggested that there is a possibility for individuals to move beyond the limits of their family habitus (see Hoskins 2013, p. 72). This explains why some students' respondents from workingclass background, such as Jie, Jiang, Wei, Lan and Song, compensated by the guanxi established with teachers, eventually achieved success to their ideal PG educational destination despite their limited family cultural and social capital. Echoing with the findings of Oliver and Kettley (2010) and Lichtenstein et al. (2014), the paper showed particularly how teachers' personal beliefs, as well as teaching methods and styles, influenced student's pathways to higher education and their choice of subject for PG studies, which is still very rare in the Chinese educational context.

The profound influence of teachers and parents on student educational choices has a connection with the Chinese culture of Confucianism. Confucianism attaches great importance to education. Thus, the poem 'Urge to Study' in ancient China was created, with the famous sentence 'Golden mansions and maidens as beautiful as jade are to be found in books' (Shuzhongziyouyanruyu, shuzhongziyouhuangjinwu), which was recounted to generations of children (Altbach and Yu 2012, p. 7). Based on the central ideals of Confucianism, the civil service examination in ancient China was created. Those who passed could become a government official and thus attain prosperity (Altbach and Yu 2012). Thus, a university degree was seen as a safe box, ensuring them a better life than those who did not have a university degree, as university graduates are found jobs (Wu 2011; Ma 2012). Even in modern Chinese society, the ideal is still 'All pursuits are of low value; only learning is high' (wanbanjiexiapin, weiyoudushugao) accepted by many (Altbach and $\mathrm{Yu}$ 2012, p. 8). As a result, many families regard making huge investment in their children's education as their top priority ( $\mathrm{Yu}$ and Suen 2005). Therefore, the choice of higher education often reflects a range of different family members' expectations and motivations.

Given the great importance attached to education, Chinese students are required to revere their teachers. Such sayings as 'a teacher is a parent' or 'my teacher for a day is a parent for a lifetime' are widely accepted among Chinese students (Anonymous 2009). Coughlan (2013) also reported that teachers in China were given the highest level of public respect based on an international study and attributed this phenomenon mainly to its strong cultural emphasis placed on the importance of education. The positive influence of teacher habitus is though-provoking as it suggested an alternative route for those disadvantaged students. Being exempt from cultural capital endowment, they could turn to their teachers' experience and connections for help. To a certain degree, teachers might be able to offset students' deficiency in family cultural capital. This is especially important in the age when the new fee-charging system of PG education in China poses a great threat to those disadvantaged students. This points to the necessity of engaging the hearts and minds of teachers, as they might be able to shape students' educational and occupational destinations ultimately (Oliver and Kettley 2010).

Explorative in essence, this research considered only the case of one university in GD Province and may not generalize the findings to the whole Chinese PG students. Consequently, it is suggested that further research should be conducted in other universities and provinces to obtain a more comprehensive picture of the factors influencing students' choice of PG education in China.

Open Access This article is distributed under the terms of the Creative Commons Attribution 4.0 International License (http://creativecommons.org/licenses/by/4.0/), which permits unrestricted use, distribution, and reproduction in any medium, provided you give appropriate credit to the original author(s) and the source, provide a link to the Creative Commons license, and indicate if changes were made.

\section{Appendix 1}

See Table 1. 
Table 1 Demographic data of the participants in the questionnaire

\begin{tabular}{|c|c|c|c|c|}
\hline \multirow{2}{*}{$\begin{array}{c}\text { Gender } \\
\text { Male }\end{array}$} & \multicolumn{2}{|r|}{ Age } & \multirow[b]{2}{*}{78} & \\
\hline & 88 & $18-22$ & & \\
\hline \multirow{3}{*}{ Female } & & $23-25$ & \multicolumn{2}{|l|}{280} \\
\hline & 293 & $26-28$ & \multicolumn{2}{|l|}{14} \\
\hline & & 28 and over & \multicolumn{2}{|l|}{2} \\
\hline \multicolumn{2}{|l|}{ Ethnicity } & \multicolumn{3}{|l|}{ UG university } \\
\hline Han & 367 & GD Province & \multicolumn{2}{|l|}{101} \\
\hline Minority & 14 & Outside GD & \multicolumn{2}{|l|}{277} \\
\hline \multicolumn{2}{|c|}{ Hometown (province) } & \multicolumn{3}{|l|}{ Hometown } \\
\hline \multirow[t]{2}{*}{ GD Province } & 76 & Countryside & \multicolumn{2}{|l|}{109} \\
\hline & & County & 49 & \\
\hline \multirow[t]{2}{*}{ Outside GD } & 304 & Small city & \multicolumn{2}{|l|}{119} \\
\hline & & Medium and big city & \multicolumn{2}{|l|}{98} \\
\hline \multicolumn{2}{|l|}{ Siblings } & \multicolumn{3}{|c|}{ Parents' education (F: left, M: right) } \\
\hline \multirow[t]{2}{*}{0} & \multirow[t]{2}{*}{166} & Elementary school or below & 31 & 59 \\
\hline & & Junior middle school & 104 & 96 \\
\hline 1 & 105 & Senior middle school & 179 & 165 \\
\hline 2 & 59 & University and college & 58 & 39 \\
\hline 3 and over & 41 & $\mathrm{PG}$ and $\mathrm{PhD}$ & 7 & 0 \\
\hline \multicolumn{2}{|c|}{ Work experience } & \multicolumn{3}{|l|}{ Ways of entrance } \\
\hline Yes & 80 & PG entrance examinations & 326 & \\
\hline No & 301 & Academic recommendation & 55 & \\
\hline \multicolumn{3}{|l|}{ Parents' job } & Father & Mother \\
\hline \multicolumn{3}{|c|}{ General technical personnel } & 26 & 6 \\
\hline \multicolumn{3}{|c|}{ Middle and senior level technical personnel } & 8 & 1 \\
\hline \multicolumn{3}{|c|}{ Other professional (scientist, teacher, engineer, accountant, lawyer, doctor, performer and others) } & 53 & 54 \\
\hline \multicolumn{3}{|c|}{ Staff of the party, government, army and others } & 31 & 12 \\
\hline \multicolumn{3}{|c|}{ Staff of enterprises and public institutions } & 45 & 44 \\
\hline Staff of busine & & & 24 & 31 \\
\hline Family busine & & & 58 & 42 \\
\hline Worker & & & 51 & 33 \\
\hline Farmer & & & 57 & 58 \\
\hline Unemployed & & & 18 & 70 \\
\hline Other occupat & & & 7 & 23 \\
\hline
\end{tabular}

\section{Appendix 2}

See Table 2.

Table 2 Demographic data of the participants in the interview

\begin{tabular}{lccr}
\hline Gender & Age & 3 & 24 \\
Male & 10 & $18-22$ & 2 \\
& & $23-25$ & 1 \\
Female & 20 & $26-28$ & 3 \\
Ethnicity & & 28 and over & 27 \\
Han & 28 & UG university & GD Province \\
Minority & 2 & Outside GD & \\
\hline
\end{tabular}


Table 2 continued

\begin{tabular}{|c|c|c|c|c|}
\hline \multicolumn{2}{|c|}{ Hometown (province) } & \multicolumn{3}{|l|}{ Hometown } \\
\hline \multirow[t]{2}{*}{ GD Province } & \multirow[t]{2}{*}{2} & Countryside & 10 & \\
\hline & & County & 4 & \\
\hline \multirow[t]{2}{*}{ Outside GD } & \multirow[t]{2}{*}{28} & Small city & 7 & \\
\hline & & Medium and big city & 9 & \\
\hline Siblings & & Parents' education (F: left, M & & \\
\hline 0 & 15 & Elementary school or below & 9 & 10 \\
\hline 1 & 8 & Middle school & 10 & 12 \\
\hline 2 & 3 & University and college & 10 & 8 \\
\hline 3 and over & 4 & $\mathrm{PG}$ and $\mathrm{PhD}$ & 1 & 0 \\
\hline
\end{tabular}

\section{References}

Altbach, P. G., \& Yu, K. (2012). Tertiary education at a glance: China. Taipei: Sense Publishers.

Anonymous. (2009). Teaching international students. In Teaching international students'staff blog on community@Brighton. University of Brighton. http://staffcentral.brighton.ac.uk/clt/ international/7eTeacherStudent.html.

Anonymous. (2013). China ends free postgraduate education. http://www.scienceguide.nl/201302/china-ends-free-postgraduateeducation.aspx.

Atkinson, W. (2011). From sociological fictions to social fictions: Some Bourdieusian reflections on the concepts of 'institutional habitus' and 'family habitus'. British Journal of Sociology of Education, 32(3), 331-347.

Ball, S. J. (2003). Class strategies and the education market: The middle classes and social advantage. London: Routledge.

Bian, Y. J. (1997). Bringing strong ties back in: indirect ties, network bridges, and job searches in China. American Sociological Review, 62(3), 366-385.

Bian, Y. J. (2006). Guanxi. In J. Beckert \& M. Zafirovski (Eds.), International encyclopedia of economic sociology (pp. 312314). New York: Greenwood Press.

Bourdieu, P. (1977). Outline of a theory of practice. Cambridge, MA: Cambridge University Press.

Bourdieu, P. (1986). The forms of capital. In J. E. Richardson (Ed.), Handbook of theory of research for the sociology of education (pp. 241-258). New York: Greenwood Press.

Chen, C., Chen, X., \& Huang, S. (2013). Chinese Guanxi: An integrative review and new directions for future research. Management and Organization Review, 9(1), 167-207.

Coughlan, S. (2013, October 14). Teachers in China given highest level of public respect. BBC News. http://www.bbc.co.uk/news/ education-24381946.

DiMaggio, P. (1982). Cultural capital and school success: The impact of status culture participation on the grades of U.S. high school students. American Sociology Review, 47(2), 189-201.

Fang, W., \& Wang, S. (2014). Chinese students' choice of transnational higher education in a globalized higher education market: A case study of W University. Journal of Studies in International Education,. doi:10.1177/1028315314523989.

Fredman, N. (2015). Understanding motivation for study: Human capital or human capability? International Journal of Training Research, 12(2), 93-105.

Gao, L. (2011). Impacts of cultural capital on student college choice in China. Lanham, MD: Lexington Books.

Hemsley-Brown, J., \& Oplatka, I. (2015). University choice: What do we know, what don't we know and what do we still need to find out? International Journal of Educational Management, 29(3), 254-274.

Hoskins, K. (2013). Senior female academics in the UK academy: Theoretical perspectives for understanding the impact of education and familial influences on career success. International Studies in Sociology of Education, 23(1), 56-75.

Huang, Y.-H. (2003). A Chinese perspective of intercultural organization-public relationship. Intercultural Communication Studies, XII(4), 251-276.

Jenkins, R. (2002). Pierre Bourdieu (revised edition). London: Routledge.

Lai, A. P. C., Gibson, P., \& Muthaly, S. (2014). Becoming an education provider of choice in Hong Kong: An inquiry into student decision making. International Journal of Educational Management, 28(5), 590-609.

Lee, K. C. C., \& Morrish, C. S. (2012). Cultural values and higher education choices: Chinese families. Australasian Marketing Journal, 20(1), 59-64.

Lichtenstein, G., Tombari, M. L., Sheppard, S. D., \& Storm, K. (2014). Does teaching matter? Factors that influence high school students' decisions whether to pursue college STEM majors. In Paper presented at the 121st ASEE annual conference and exposition, Indianapolis, IN.

Liu, J. (2010). The changing body of students: A study of the motives, expectations and preparedness of postgraduate marketing students. Marketing Intelligence and Planning, 28(7), 812-830.

Liu, X., Elston, F., \& Zhou, P. (2014). Comparing research on Chinese students study abroad decision-making: China-based versus overseas-based perspectives. World Review of Business Research, 4(3), 124-135.

Liu, Y., Hung, F. S., \& Chung, Y. P. (2013). Chinese students' choice of major when considering higher education abroad: The case of mainland China. China: An International Journal, 11(1), 94-112.

Ma, W. (2012). Why the rural poor get fewer opportunities to leading research universities. Asia Pacific Education Review, 13(2), 263-271.

McDonough, P. M. (1997). Choosing colleges: How social class and schools structure opportunity. Albany: State University of New York Press.

NBSC. (2014). China statistical yearbook 2014. http://www.stats.gov. $\mathrm{cn} / \mathrm{tjsj} / \mathrm{ndsj} / 2014 /$.

Obermeit, K. (2012). Students' choice of universities in Germany: Structure, factors and information sources used. Journal of Marketing for Higher Education, 22(2), 206-230.

Oliver, C., \& Kettley, N. (2010). Gatekeepers or facilitators: The influence of teacher habitus on students' applications to elite universities. British Journal of Sociology of Education, 31(6), 737-753. 
Qi, X. (2013). Guanxi, social capital theory and beyond: Toward a globalized social science. The British Journal of Sociology, 64(2), 308-324.

Reay, D. (1998). 'Always knowing' and 'never being sure': Familial and institutional habituses and higher education choice. Journal of Education Policy, 13(4), 519-529.

Reay, D. (2004). 'It's all becoming a habitus': Beyond the habitual use of habitus in educational research. British Journal of Sociology of Education, 25(4), 431-444.

Reay, D., David, M., \& Ball, S. (2001). Making a difference? Institutional habituses and higher education choice. Sociological Research Online, 5. http://www.socresonline.org.uk/5/4/ reay.html.

Shaw, A. (2012). Family fortunes: Female students' perceptions and expectations of higher education and an examination of how they, and their parents, see the benefits of university. Educational Studies, 39(2), 195-207.

Sheng, X. (2015). Gender and habitus: Parental involvement in students' subject choices in China. Journal of Gender Studies, 24(2), 227-238

Smyth, E., \& Banks, J. (2012). 'There was never really any question of anything else': Young people's agency, institutional habitus and the transition to higher education. British Journal of Sociology of Education, 33(2), 263-281.

To, W. M., La, L. S. L., Lung, J. W. Y., \& Lai, T. M. (2014). Intent to pursue further studies among Chinese students. Educational Studies, 40(3), 292-309.

Tsang, E. Y.-H. (2013). The quest for higher education by the Chinese middle class: Retrenching social mobility? Higher Education, 66(6), 653-668.

$\mathrm{Wu}, \mathrm{X}$. (2011). The dynamic role of cultural capital in the competitive school admission process: A Chinese experience. Australian Educational Researcher, 39(3), 275-293.

$\mathrm{Wu}, \mathrm{X}$. (2013). The power of social capital in school choice in a Chinese city. Australian Journal of Education, 57(1), 48-59.

Wu, B., \& Morgan, W. J. (2015). Chinese higher education reform and social justice. London: Routledge.

Wu, B., \& Zheng, Y. (2008). Expansion of higher education in China: Challenges and implications. Briefing Series, 36. http://www.nottingham.ac.uk/cpi/documents/briefings/briefing36-china-higher-education-expansion.pdf.

Yu, L., \& Suen, H. K. (2005). Historical and contemporary examdriven education fever in China. KEDI Journal of Education Policy, 2(1), 17-33. 